\title{
Hospitalization costs for community- acquired pneumonia in Dutch elderly: an observational study
}

\author{
Conrad E. Vissink ${ }^{1,2^{*}}$, Susanne M. Huijts ${ }^{1,3}$, G. Ardine de Wit ${ }^{1}$, Marc J. M. Bonten ${ }^{1,4}$ and Marie-Josée J. Mangen ${ }^{1}$
}

\begin{abstract}
Background: Community-acquired pneumonia (CAP) is one of the most common infections, especially in the elderly ( $\geq 65$ years). The aim of this study was to quantify hospitalization costs for CAP in different age groups and in patients with different CAP risk profiles. Secondary objectives were to assess disease severity differences between placebo and vaccine receiving participants and identify cost driving factors of CAP in hospitalized elderly in the Netherlands.

Methods: This prospective cohort study of hospitalized CAP patients was executed in parallel to the Community Acquired Pneumonia Immunization Trial in Adults (CAPiTA). Within the CAPiTA, a cohort of 84,496 subjects aged $\geq 65$, all suspected CAP-episodes presenting in one of the 58 participating hospitals between September 2008 and August 2013 were included. CAP was diagnosed on clinical and radiographical criteria. Invasive pneumococcal disease (IPD) and non-IPD-CAP episodes, regardless of the causing pathogen, were evaluated separately. Costs were calculated by multiplying recorded healthcare resources with Dutch unit cost prices for the year 2012. Multivariate regression analysis was performed to identify cost drivers.
\end{abstract}

Results: In the sentinel hospitals 3225 suspected CAP and IPD episodes were included, of which 1933 were radiographically confirmed by chest X-ray. Analyses were conducted on confirmed CAP episodes only. Overall mean length of hospital stay was 12.1 days, the in-hospital mortality rate was $11.26 \%$, and mean costs were $€ 8301$ (95\% Cl: $€ 7760-€ 8999)$. When stratified in age-categories $65-74,75-84$ and $\geq 85$, mean hospitalization costs were $€ 8674$, $€ 8770$ and $€ 6197$, respectively $(p=0.649)$. IPD-CAP and non-IPD-CAP mean hospitalization costs were $€ 13,611$ and $€ 8081$, respectively. Higher CURB-65 score and individuals at medium risk for developing pneumococcal disease were significantly associated with higher costs. Being male, lower age, previous admissions, lower risk, lower urbanity and higher socio-economic status were associated with lower costs.

Conclusions: Mean hospitalization costs of a CAP subject were €8301 and higher for IPD-CAP compared to non-IPD-CAP cases. Medium risk patients and higher CURB-65 scores were identified as cost driving factors.

Keywords: Community-acquired pneumonia, Costing study, Elderly, Hospitalization, Invasive pneumococcal disease, Risk-groups

Abbreviations: CAP, Community-acquired pneumonia; CAPiTA, Community Acquired Pneumonia Immunization Trial in Adults; Cl, Confidence interval; DBC, Diagnosis Related Groups (in Dutch: Diagnose Behandel Combinatie); EtioCAP, Etiology and prognosis of community-acquired pneumonia study; GP, General practice; ICD, International Classification of Diseases; ICU, Intensive care unit; IPD, Invasive pneumococcal disease; IPD-CAP, Community-acquired (Continued on next page)

\footnotetext{
* Correspondence: c.e.vissink-2@umcutrecht.nl

1 Julius Center for Health Sciences and Primary Care, University Medical

Center Utrecht, Utrecht, The Netherlands

${ }^{2}$ Present address: Department of Psychiatry, University Medical Center

Utrecht, A01.126 Heidelberglaan 100, Utrecht 3508, GA, The Netherlands

Full list of author information is available at the end of the article
} 
(Continued from previous page)

pneumonia patients with invasive pneumococcal disease; LOS, Length of stay; non-IPD-CAP, Community-acquired pneumonia patient without invasive pneumococcal disease; PCV13, 13-valent pneumococcal vaccine; PSI, Pneumonia Severity Index

\section{Background}

Community-acquired pneumonia (CAP) is one of the most common infectious diseases in the world [1-4]. In Europe, the incidence of all-cause CAP (hospitalized and outpatient) in the elderly population ( $\geq 65$ years) is estimated at 14 per 1000 person years $[5,6]$. Approximately $56 \%$ (equal to $€ 5.7$ billion) of CAPs economic burden in Europe is ascribed to hospitalization expenses [7]. The other costs can be attributed to outpatient care, loss of workdays and drug expenses. Increasing CAP incidence due to growth of the elderly population in the upcoming years [8-11], more severe episodes due to increasing comorbidity within the aging population [12], and limited economic resources demand for new preventive measures [13]. In Western countries like the Netherlands, new healthcare interventions will be evaluated for their costs and effects and detailed cost estimates are indispensable in this process. However, most larger studies describing CAP costs were conducted retrospectively and based on insurance claims with limited clinical information [4, 14-19]. The few prospective studies on CAP hospitalization costs covered relative small cohorts only [20-22].

The Community Acquired Pneumonia Immunization Trial in Adults trial (CAPiTA), a nation-wide study assessing the efficacy of the 13-valent pneumococcal vaccine (PCV13) in the elderly, created a unique opportunity for quantifying hospitalization costs of CAP [23, 24]. A parallel study was designed to estimate costs for hospitalized CAP patients, including patients with and without invasive pneumococcal disease (IPD), stratified by ageand risk-groups for developing pneumococcal infections and by outcome (i.e. mortality). Secondary objectives were to analyze disease severity differences between PCV13 and placebo cohorts and to identify cost drivers in hospitalized CAP cases.

\section{Methods}

\section{Study subjects}

The etiology and prognosis of community-acquired pneumonia (Etio-CAP) study is a prospective cohort study conducted in parallel to CAPiTA [23, 24]. In this double blind randomized clinical vaccination trial in the Netherlands, the efficacy of PCV13 in adults was evaluated by vaccinating 84,496 subjects of $\geq 65$ years of age with either placebo or PCV13 with an average follow-up period of 3.97 years [24]. Detailed information, in- and exclusion criteria and outcome measures have been previously described [23, 24]. Follow-up was organized in 59 sentinel centers (58 hospitals and 1 outpatient clinic) between September 2008 and August 2013, where the 58 hospitals participated in the EtioCAP study. When a CAPiTA-participant was registered to one of these hospitals with a suspicion of pneumonia, regardless of the causing pathogen, clinical data were collected according to the CAPiTA protocol. When admitted, additional data, like use of resources and complications, were collected as part of the Etio-CAP-study.

\section{Definitions}

CAP was defined, regardless of the causing pathogen, as the presence of two or more clinical signs of pneumonia together with a chest $\mathrm{x}$-ray consistent with pneumonia [23]. IPD was defined as Streptococcus pneumoniae cultured from a sterile site (e.g. blood). The analysis was conducted for three groups: 'total CAP' (i.e. all confirmed CAP cases), non-IPD-CAP (i.e. confirmed CAP cases, no IPD) and 'IPD-CAP' (i.e. cases with confirmed CAP and IPD). Subjects with IPD without CAP were not included in the analyses.

Admissions within 30 days post-discharge of a suspected CAP hospitalization episode were labeled as a readmission and treated as a continuation of the previous admission with regard to a) diagnosis (CAP or IPD) and b) costs (i.e. resources used in first and following admissions, and associated costs were added up).

The study was approved by the Central Committee on Research Involving Human Subjects (CCMO11.0810/ TV/NL23014) as a sub-study of the CAPiTA-trial. Therefore no separate informed consent was required for the Etio-CAP study.

\section{Data collection}

Data collected included length of stay (LOS) and intensive care unit (ICU) admission, comorbidities at moment of admission (see Additional file 1: Table S1), date of symptom onset and date of symptom relieve. Based on the presence of comorbidities, subjects were stratified into high (i.e. immunocompromised patients), medium (i.e. presence of other chronic conditions) and low risk for pneumococcal infections (Additional file 1: Table S1).

Data included for the Etio-CAP-study concerned: mortality (with minimum follow-up of 6 months after hospital admission, i.e. confirmation of vital status by the GP of the participant), laboratory results, number of 
hospital admissions 1 year prior to index CAP hospitalization episode, diagnostic and therapeutic interventions for both pneumonia and its complications, additional "waiting days" in the hospital (i.e. before home care could be organized), and location of discharge (own home or nursing home). Pneumonia severity was assessed using the Pneumonia severity index (PSI), as described by Fine et al. [25], and CURB-65 [26]. PSI score was categorized into low (score 1 and 2), medium (score 3 and 4) and high (score 5). Based on postal codes, information on socioeconomic status (continues variable from low to high, scores ranging from -5.5 to 3, with lower scores reflecting lower socio-economic status) and urbanity of neighborhood (from high to low; score 1, 2, 3, 4 and 5) was obtained from Statistics Netherlands and referred to the situation in 2010 [27].

\section{Costs}

Hospitalization costs were calculated by multiplying recorded units of healthcare resources used with corresponding unit prices (see Additional file 1: Table S2) [28]. Unit costs were either taken from the Dutch manual for healthcare costing research $[28,29]$ or were calculated from a unit price medium of different hospital price lists available. All costs were expressed for the year 2012, and if necessary, updated using Dutch consumer price indices [30].

\section{Statistical Analysis}

Data were analyzed using IBM SPSS Statistics for Windows, Version 20.0. The one-way ANOVA test, Mann-Whitney U-test and the Kruskal-Wallis test were used to compare quantitative variables and the Chisquare test was used for categorical variables. Intubation days at the ICU were recorded in a dichotome (yes or no) and a quantitative way (e.g. number of days of intubation). There were no missing data with the exception of number of intubated ICU days $(0.6 \%)$ and number of previous admissions $(0.2 \%)$. Missing data were imputated using multiple imputation. A stepwise multiple regression model was used to identify cost drivers with log-transformed hospitalization costs as a dependent variable. Explanatory variables were gender, age, previous admission (categorized as: none, one, two, three or more admissions), smoking status (non-smoker, previous smoker, current smoker), risk-level, socioeconomic status and urbanity, and CURB-65. The latter was used instead of PSI scoring, because of overlapping definitions between PSI and risk levels as both are estimated using comorbidity information. The $95 \%$ confidence interval (CI) was determined using bootstrapping with 1000 iterations. A $p$-value of $<0.05$ was considered significant.

\section{Results \\ Study participants}

There were 3225 registered suspected CAP episodes, of which 138 were not hospitalized. Of these suspected and hospitalized CAPs 1154 cases were not confirmed as CAP (i.e. no positive chest X-rays and/or $<2$ clinical signs of pneumonia) and consequently excluded from the analysis (Fig. 1). Of the remaining 1933 confirmed CAP admissions, 148 were readmissions, yielding 1785 episodes for analysis. Of these, 74 had IPD-CAP and 1714 had non-IPD-CAP) (Fig. 1).

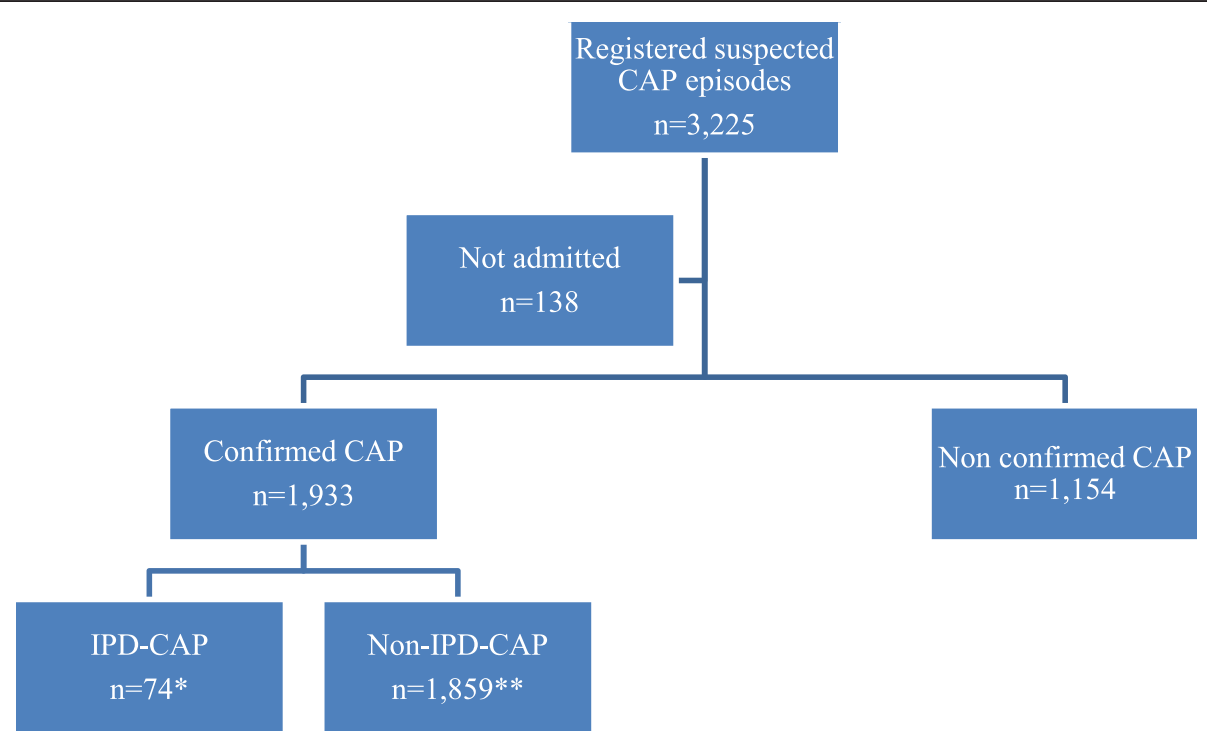

Fig. 1 Flowchart of the study. Legend: *Including 3 readmissions; **Including 145 readmissions. Abbreviations: CAP: community-acquired pneumonia; IPD-CAP: invasive pneumococcal disease 
The majority (73\%) of CAP patients were male, and the mean length of hospitalization was 12.1 days (95\% CI: 2-42 days) consisting of $92 \%$ ward days and $8 \%$ ICU days (Table 1). The 30-day mortality rate of low, medium and high risk-groups was 4, 10.4 and $29.1 \%$, respectively. Compared to non-IPD-CAP cases, IPDCAP cases had a longer average duration of stay in hospital $(p=0.028)$ and in ICU $(p=0.022)$ (Table 1$)$.

\section{Costs}

The mean hospitalization cost for all CAP subjects was $€ 8301$ (Median: €4809, 95 \% CI: €7760-€8999) (Table 2 and Additional file 1: Table S3). General ward nursing costs accounted for $63 \%$ of total hospitalization costs and ICU nursing for $29 \%$. When stratified by age groups $65-74$, $75-84$ and $\geq 85$ years, mean hospitalization costs were $€ 8674, € 8770$ and $€ 6197$, respectively $(p=0.649)$. The mean hospitalization costs per IPD-CAP case were significantly higher than for non-IPD-CAP cases $(€ 13,611$ versus $€ 8081, p=0.025$ ).

The mean hospitalization cost for survivors and nonsurvivors in the total CAP cohort was $€ 7638$ and $€ 13,526$, respectively $(p=0.30)$ (Figs. 2 and 3$)$. ICU costs of survivors were lower $(p<0.001)$ and ward costs were higher $(p<0.001)$ compared to non-survivors.

Comparison between subjects who received PCV13 $(n=861)$ and placebo $(n=924)$ revealed no differences in LOS (12.03 versus 12.17 days, $p=0.919$ ), PSI category (2.13 versus $2.09, p=0.368)$ and mean hospitalization

Table 1 Baseline characteristics of study population

\begin{tabular}{|c|c|c|c|c|}
\hline & Total CAP & IPD-CAP & non-IPD-CAP & $p$-value \\
\hline Admission $^{a}, \mathrm{n}$ & 1785 & 71 & 1714 & \\
\hline Age in years, mean (SD) & $77.4(6.6)$ & $76(5.5)$ & $77.5(6.7)$ & \\
\hline Male, n (\%) & $1307(73.2)$ & $43(60.6)$ & $1264(73.7)$ & * \\
\hline ReceivedPCV13, n (\%) & $861(48.2)$ & $24(33.8)$ & $837(48.8)$ & * \\
\hline \multicolumn{5}{|l|}{ Risk group for developing pneumococcal disease, n (\%) } \\
\hline - Low & $248(13.9)$ & $18(25.4)$ & $230(13.4)$ & \\
\hline - Medium & $1207(67.6)$ & $47(66.2)$ & $1160(67.7)$ & \\
\hline - High & $330(18.5)$ & $6(8.5)$ & $324(18.9)$ & \\
\hline Length of stay in days, mean (95 \% Cl) & $12.1(11.6-12.6)$ & $15.3(12.3-18.9)$ & $12.0(11.5-12.4)$ & * \\
\hline - Ward days, mean (95 \% Cl) & $11.1(10.7-11.6)$ & $13.0(10.3-15.8)$ & $11.1(10.6-11.5)$ & \\
\hline - $\quad$ ICU days, mean (95 \% Cl) & $1.0(0.8-1.2)$ & $2.4(0.9-4.2)$ & $0.9(0.7-1.1)$ & * \\
\hline - Intubationdays, mean (95% Cl) & $0.4(0.3-0.6)$ & $1.1(0.3-2.2)$ & $0.4(0.3-0.6)$ & * \\
\hline Illness duration in days ${ }^{b}$, mean $(95 \% \mathrm{Cl})$ & $16.9(16.3-17.5)^{c}$ & $19.8(16.1-24.1)$ & $16.7(16.1-17.4)^{\complement}$ & \\
\hline Days between onset and hospital admission, mean (95 \% Cl) & $4.9(4.6-5.2)^{d}$ & $4.3(2.7-6.8)$ & $4.9(4.6-5.3)^{d}$ & \\
\hline \multicolumn{5}{|l|}{ Pneumococcal severity index (PSI), n (\%) } \\
\hline$\cdot|-| \mid$ & $126(7.1)$ & $5(7.0)$ & $121(7.1)$ & \\
\hline - $\quad||-\mid V$ & $1327(74.3)$ & $48(67.6)$ & $1279(74.6)$ & \\
\hline - $\mathrm{V}$ & $332(18.6)$ & $18(25.4)$ & $314(18.3)$ & \\
\hline In-hospitalmortality, n (\%) & $201(11.3)$ & $11(15.5)$ & $190(11.1)$ & \\
\hline 30-day mortality, n (\%) & $235(13.2)^{\mathrm{e}}$ & $11(15.5)$ & $224(13.1)^{\mathrm{e}}$ & \\
\hline 60-day mortality, n (\%) & $300(16.8)^{e}$ & $12(16.9)$ & $288(16.8)^{e}$ & \\
\hline 6-months mortality, n (\%) & $444(24.9)^{e}$ & $18(25.4)$ & $426(24.9)^{\mathrm{e}}$ & \\
\hline Location of discharge, n (\%) & $1584(88.7)$ & $60(84.5)$ & $1524(88.9)$ & \\
\hline - Home & $1371(86.6)$ & $51(85.0)$ & $1320(86.6)$ & \\
\hline - Nursing home & $160(10.1)$ & $8(13.3)$ & $152(10)$ & \\
\hline - Others & $53(3.3)$ & $1(1.7)$ & $52(3.4)$ & \\
\hline
\end{tabular}

*Statistically significant difference between non-IPD-CAP and IPD-CAP

admissions within 30 days post-discharge of a suspected CAP hospitalization episode were labeled as a readmission and analyzed as a continuation of the previous admission

${ }^{\mathrm{b}}$ Number of days from onset to hospital discharge

c11 with missing data

d9 with missing data

e 2 with missing data 
Table 2 Hospitalization costs of CAP and IPD-CAP subjects stratified by age- and risk-groups in $2012 €$

\begin{tabular}{|c|c|c|c|c|c|c|}
\hline \multirow[t]{2}{*}{ Population } & \multirow[t]{2}{*}{$\begin{array}{l}\text { Age group } \\
\text { (years) }\end{array}$} & \multirow[t]{2}{*}{$\begin{array}{l}\text { Risk } \\
\text { level }\end{array}$} & \multirow[t]{2}{*}{$\mathrm{N}$} & \multirow[t]{2}{*}{ Mean } & \multicolumn{2}{|c|}{$\begin{array}{l}95 \% \text { Confidence } \\
\text { Interval }\end{array}$} \\
\hline & & & & & Lower & Upper \\
\hline \multirow[t]{13}{*}{ Total CAP } & All & & 1,785 & 8,301 & 7,760 & 8,999 \\
\hline & \multirow[t]{4}{*}{$65-74$} & All & 678 & 8,674 & 7,841 & 9,641 \\
\hline & & Low & 87 & 8,418 & 5,870 & 11,696 \\
\hline & & Medium & 445 & 9,118 & 7,921 & 10,407 \\
\hline & & High & 146 & 7,472 & 6,163 & 9,248 \\
\hline & \multirow[t]{4}{*}{$75-84$} & All & 807 & 8,770 & 7,748 & 9,847 \\
\hline & & Low & 73 & 10,387 & 7,222 & 14,516 \\
\hline & & Medium & 574 & 8,270 & 7187 & 9,550 \\
\hline & & High & 160 & 9,828 & 7,345 & 12,811 \\
\hline & \multirow[t]{4}{*}{$\geq 85$} & All & 300 & 6,197 & 5,677 & 6,764 \\
\hline & & Low & 42 & 6,042 & 4,978 & 7,188 \\
\hline & & Medium & 227 & 6,198 & 5,606 & 6,832 \\
\hline & & High & 31 & 6,401 & 5,039 & 8,238 \\
\hline \multirow[t]{13}{*}{ IPD-CAP } & All & & 71 & 13,611 & 8,612 & 20,434 \\
\hline & \multirow[t]{4}{*}{$65-74$} & All & 31 & 11,635 & 6,996 & 17,982 \\
\hline & & Low & 8 & 16,185 & 5,336 & 34,137 \\
\hline & & Medium & 20 & 10,615 & 5,831 & 17,142 \\
\hline & & High & 3 & 6,299 & 3,815 & 8,960 \\
\hline & \multirow[t]{4}{*}{$75-84$} & All & 34 & 16,496 & 7,650 & 30,360 \\
\hline & & Low & 6 & 18,837 & 3,880 & 41,063 \\
\hline & & Medium & 25 & 16,903 & 6,182 & 35,483 \\
\hline & & High & 3 & 8,416 & 1,268 & 21,697 \\
\hline & \multirow[t]{4}{*}{$\geq 85$} & All & 6 & 7,478 & 3,456 & 12,416 \\
\hline & & Low & 2 & 7,440 & 3,860 & 11,020 \\
\hline & & Medium & 4 & 7,497 & 2,238 & 16,577 \\
\hline & & High & 0 & - & - & - \\
\hline
\end{tabular}

Due to minimal differences between total CAP and non-IPD-CAP cohorts costs, the latter are presented in Additional file 1: Table S3

costs ( $€ 8115$ versus $€ 8475, p=0.835$ ). Furthermore, LOS, PSI category and costs were similar for subjects with IPDCAP and non-IPD-CAP.

\section{Cost drivers}

A high CURB-65 score and medium risk profile for pneumococcal CAP were associated with higher hospitalization cost (Table 3). Male gender, increasing age, one or more previous admissions in the past year, low risk profile for pneumococcal CAP, lower urbanity and higher socio-economic status were associated with lower costs.

\section{Discussion}

Among those who participated in the CAPiTA-study, the mean costs of hospitalization for CAP were $€ 8301$.
Costs for a hospitalized CAP episode with IPD were $€ 13,611$, or $168 \%$ of the mean costs for a non-IPD-CAP episode (i.e. $€ 8081$ ). A high clinical severity of disease at the time of hospitalization and having medium risk profile for pneumococcal disease were identified as independent drivers of high costs, whereas male gender, increasing age, previous admission(s) in the past year, low risk profile for pneumococcal CAP, lower urbanity and higher socio-economic status were associated with lower overall costs. Vaccination status was not associated with clinical severity of CAP or costs of hospitalization.

Quantification of costs associated with CAP are usually based on retrospective studies using national insurance claims databases. In a previous retrospective study in Netherlands by Spoorenberg et al. [20], median costs based on ICD recordings were estimated at $€ 3899$. In the current study median costs were $€ 4809$, and the difference could be explained by the younger cohort in the Spoorenberg et al. study (mean age 63.4 versus 77.4) potentially leading to a shorter LOS (8.5 versus 12 days) and a lower case-fatality rate (30-day mortality: 5.1 versus $13.1 \%)$. Furthermore, in the current study, nonsurvivor costs were $€ 13,526$ and appeared to be $177 \%$ of the hospitalization costs of survivors (i.e. €7638). Also, Spoorenberg et al. did not consider the additional costs of readmissions and included patients of only two general hospitals in the Netherlands, as compared to 58 hospitals, of which seven are tertiary care centers, were included in the current study. Indeed, the proportion of patients needing ICU admission was $21.2 \%$ in tertiary care (24/113) and $12.1 \%$ in general hospitals (202/1672).

Another nationwide ICD-based cost analysis by Rozenbaum et al. [19] reported medium costs of CAP of $€ 6060$ and $€ 5937$ in those $65-74$ and $75-84$ years of age, respectively, which is also lower than the medium costs for these age cohorts in the current study (€8674 and $€ 8770$, respectively). The study by Rozenbaum et al. was based on reimbursement of hospital expenses, as regulated by Diagnosis Related Groups (in Dutch: Diagnose BehandelCombinatie or DBC). By selecting solely DBCs related to pneumonia, other costs (e.g. treatment of complications) were not considered, possibly explaining the lower costs. Also readmissions were not taken into account, resulting in shorter length of stay in the 65-74 and 75-84 age cohorts (7.7 versus 12.4 and 8.1 versus 12.3, respectively). Furthermore, the use of ICD-coding in both Dutch studies [19, 20] may have caused important misclassification. In another Dutch study across seven Dutch hospitals, the sensitivity of ICD-coding was estimated at $79.5 \%$ [31]. The current prospective study with 1933 patients with confirmed CAP based on standardized diagnostic criteria may, therefore, be more precise and generalizable than previous studies [16, 19-22]. 


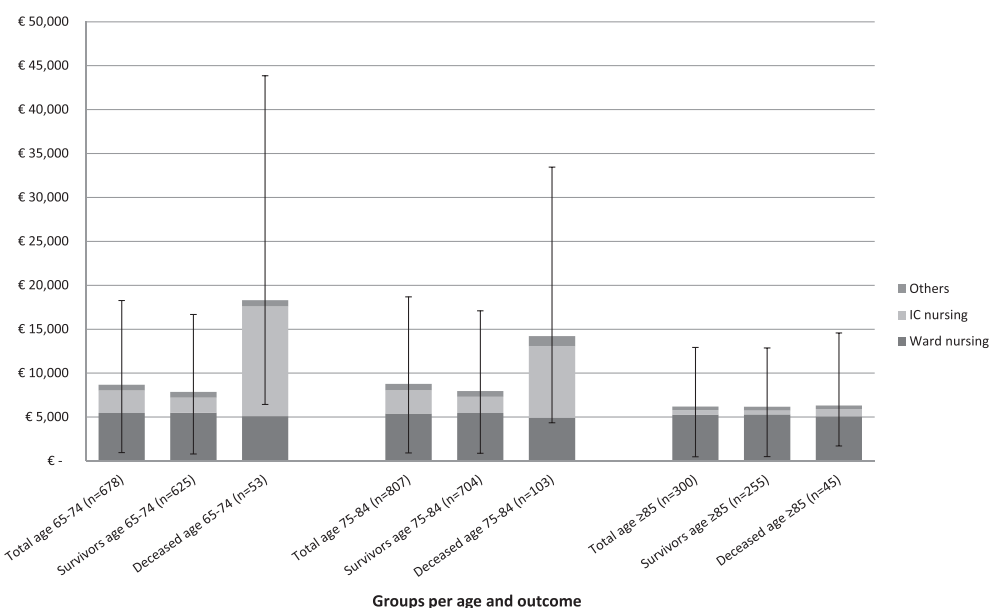

Fig. 2 Mean CAP-related hospitalization cost for the total CAP cohort, survivors and deceased persons stratified by age. Error-bars depicting the $95 \%$ confidence interval of the mean. Results obtained using boostrapping

Different settings and healthcare systems makes a comparison between countries nearly impossible at the level of cost estimates [32]. Length of Stay (LOS) has been identified as a major contributor to healthcare resource utilization. We found a mean of 12 days which is within the range of other European studies, [21, 22, 33-40], ranging from 8 up to 13.2 days.

There are also limitations of this study that need to be addressed. An exclusion criterion for the CAPiTA-trial was the presence of immunodeficiency (i.e. individuals at high risk for developing pneumococcal infections), except for patients with asplenia. However, there were 330 (18.5 \%) patients with CAP that had developed immune deficiencies after enrollment in the CAPITAtrial. Hospital costs might be slightly underestimated as we did not have exact information on the percentage of patients that received in-hospital rehabilitation services, or because some diagnostic or therapeutic procedures, such as incidental pleural punctures, may not have been reported. Additionally, in the current cohort $10.1 \%$ of the survivors were discharged to a nursing home or rehabilitation center. As information on the total length of stay in nursing home or rehabilitation center was lacking, we could not add these costs to our cost estimates.

\section{Conclusion}

The current study showed variability in hospitalization cost between different ages, disease severities and survival status. The eldest group experienced high mortality and shorter ICU admission. Mean hospitalization

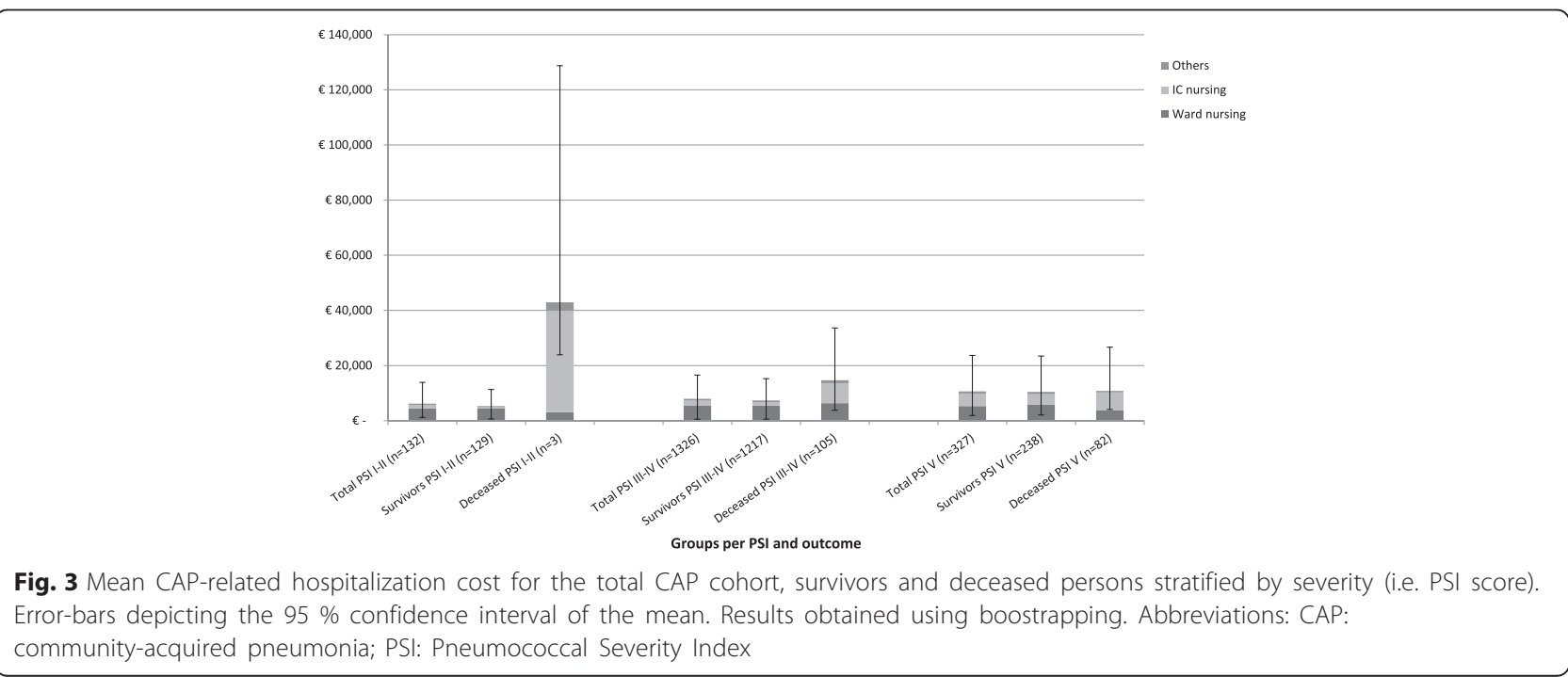


Table 3 Cost driving factors in the CAPcohort

\begin{tabular}{lcll}
\hline & \multicolumn{3}{l}{ Multiple regression } \\
\cline { 2 - 4 } & $\beta$ & SE & $p$-value \\
\hline Constant & 9.23 & 0.06 & $<0.001$ \\
Male & -0.06 & 0.01 & $<0.001$ \\
Age & -0.01 & 0.00 & $<0.001$ \\
Previous admission & -0.03 & 0.00 & $<0.001$ \\
CURB-65 & 0.12 & 0.01 & $<0.001$ \\
Low risk & -0.09 & 0.02 & $<0.001$ \\
Medium risk & 0.03 & 0.01 & 0.049 \\
Urbanity & -0.03 & 0.00 & $<0.001$ \\
Socioeconomic status & -0.01 & 0.00 & 0.02 \\
\hline
\end{tabular}

cost for a CAP subject was $€ 8301$. Costs are significantly higher for IPD-CAP than for non-IPD-CAP cases. With an aging population and a rising life expectancy the disease and economic burden may further increase in the near future.

\section{Additional files}

Additional file 1: Table S1. Comorbidities considered at increased risk for developing pneumococcal infections; Table S2. Unit cost prices; Table S3. Hospitalization costs of non-IPD-CAP subject stratified by age- and risk-category in $2012 €$.

\section{Funding}

The Etio-CAP study and the CAPiTA-trial are made possible by an unrestricted grant from Wyeth Pharmaceuticals (now Pfizer Inc.) to the University Medical Center of Utrecht (UMCU). Pfizer Inc. (the sponsor) had no role in the design, analysis, interpretation of the data, or the writing of the manuscript. Pfizer Inc. did review a penultimate version of the manuscript.

\section{Availability of data and material}

The data used in this paper were obtained from a third party and are therefore only available on request. These data from the CAPiTA-trial and from the Etio-CAP study may be requested by contacting Marie-Josée Mangen (m.j.j.mangen@umcutrecht.nl) or Susanne Huijts (s.m.huijts@umcutrecht.nl).

\section{Authors' contributions}

$\mathrm{SMH}, \mathrm{MJMB}$ and MJJM contributed to conception and design of the study. $\mathrm{SMH}$ and MJMB drafted the approved study protocol. CEV, MJJM and SMH conducted the data analysis. CEV drafted the current manuscript. GAdW, MJMB, MJJM and SMH critically revised the current manuscript. All authors read and approved the final manuscript.

\section{Competing interests}

MJMB reports receipt of research funding from Pfizer, and service on the CAPITA European Expert Meeting. SMH's research funding is partially supported by grants provided to UMCU (University Medical Center Utrecht) by Pfizer. MJJM's research funding is partially supported by grants provided to UMCU by Pfizer. GAdW reports receipt of an unrestricted research grant from Pfizer. SMH, MJMB, GAdW and MJJM are employed by UMCU. CEV was a Master student doing an internship at UMCU when performing this study. The authors declare that they have no other competing interests.

\section{Consent for publication}

Not applicable.

\section{Ethics approval and consent to participate}

The study was approved by the Central Committee on Research Involving Human Subjects (CCMO11.0810/TV/NL23014) as a sub-study of the CAPiTA-trial. Therefore no separate informed consent was required for the Etio-CAP study.

\section{Author details}

'Julius Center for Health Sciences and Primary Care, University Medical Center Utrecht, Utrecht, The Netherlands. ${ }^{2}$ Present address: Department of Psychiatry, University Medical Center Utrecht, A01.126 Heidelberglaan 100, Utrecht 3508, GA, The Netherlands. ${ }^{3}$ Department of Respiratory Medicine, University Medical Center Utrecht, Utrecht, The Netherlands. ${ }^{4}$ Department of Medical Microbiology, University Medical Center Utrecht, Utrecht, The Netherlands.

Received: 9 September 2015 Accepted: 16 August 2016

Published online: 02 September 2016

\section{References}

1. Carlet J, Mainardi JL. Antibacterial agents: back to the future? Can we live with only colistin, co-trimoxazole and fosfomycin? Clin Microbiol Infect. 2012;18(1):1-3.

2. Fry AM, Shay DK, Holman RC, Curns AT, Anderson LJ. Trends in hospitalizations for pneumonia among persons aged 65 years or older in the United States, 1988-2002. JAMA. 2005;294(21):2712-9.

3. Oosterheert JJ, Bonten MJ, Hak E, Lammers JW, Schneider MM, Hoepelman IM. [The increase in pneumonia-related morbidity and mortality among adults in the Netherlands and possible explanations for it.] Ned Tijdschr Geneeskd. 2004;148(36):1765-9.

4. Welte T, Torres A, Nathwani D. Clinical and economic burden of communityacquired pneumonia among adults in Europe. Thorax. 2012;67(1):71-9.

5. Vila-Corcoles A, Ochoa-Gondar O, Rodriguez-Blanco T, Raga-Luria X, Gomez-Bertomeu F, EPIVAC Study Group. Epidemiology of communityacquired pneumonia in older adults: a population-based study. Respir Med. 2009;103(2):309-16.

6. Torres A, Peetermans WE, Viegi G, Blasi F. Risk factors for community-acquired pneumonia in adults in Europe: a literature review. Thorax. 2013;68(11):1057-65.

7. Anonymous. European lung white book. 2nd ed. Sheffield: Foundation ERSEL; 2003. p. 5--65.

8. Ruhnke GW, Coca-Perraillon M, Kitch BT, Cutler DM. Trends in mortality and medical spending in patients hospitalized for community-acquired pneumonia: 1993-2005. Med Care. 2010;48(12):1111-6.

9. Trotter CL, Stuart JM, George R, Miller E. Increasing hospital admissions for pneumonia, England. Emerg Infect Dis. 2008;14(5):727-33.

10. Welte T. Community-acquired pneumonia: a disease of the elderly. $Z$ Gerontol Geriatr. 2011:44(4):221-8 (in German)

11 Yoo KH, Yoo CG, Kim SK, Jung JY, Lee MG, Uh ST, et al. Economic burden and epidemiology of pneumonia in Korean adults aged over 50 years. J Korean Med Sci. 2013;28(6):888-95.

12 Ewig S, Birkner N, Strauss R, Schaefer E, Pauletzki J, Bischoff H, et al. New perspectives on community-acquired pneumonia in 388406 patients. Results from a nationwide mandatory performance measurement programme in healthcare quality. Thorax. 2009;64(12):1062-9.

13 Postma DF, van Werkhoven CH, Huijts SM, Bolkenbaas M, Oosterheert JJ, Bonten MJ. New trends in the prevention and management of communityacquired pneumonia. Neth J Med. 2012;70(8):337-48.

14 Sato R, Gomez Rey G, Nelson S, Pinsky B. Community-acquired pneumonia episode costs by age and risk in commercially insured US adults aged >/=50 years. Appl Health Econ Health Policy. 2013;11(3):251-8.

$15 \mathrm{Yu} \mathrm{H}$, Rubin J, Dunning S, Li S, Sato R. Clinical and economic burden of community-acquired pneumonia in the Medicare fee-for-service population. J Am Geriatr Soc. 2012;60(11):2137-43.

16 Tichopad A, Roberts C, Gembula I, Hajek P, Skoczynska A, Hryniewicz W, et al. Clinical and economic burden of community-acquired pneumonia among adults in the Czech Republic, Hungary, Poland and Slovakia. PLoS One. 2013;8(8):e71375.

17 Thomas CP, Ryan M, Chapman JD, Stason WB, Tompkins CP, Suaya JA, et al. Incidence and cost of pneumonia in medicare beneficiaries. Chest. 2012; 142(4):973-81.

18 Jacob C, Mittendorf T, von der Schulenburg JM G. [Costs of illness and health-related quality of life for community-acquired pneumonia-a systematic review]. Pneumologie. 2011;65(8):498-502. in German. 
19 Rozenbaum MH, Mangen MJ, Huijts SM, van der Werf TS, Postma MJ. Incidence, direct costs and duration of hospitalization of patients hospitalized with community acquired pneumonia: A nationwide retrospective claims database analysis. Vaccine. 2015;33(28):3193-9.

20 Spoorenberg S, Bos WJ, Heijligenberg R, Voorn P, Grutters J, Rijkers G, et al. Microbial aetiology, outcomes, and costs of hospitalisation for community-acquired pneumonia; an observational analysis. BMC Infect Dis. 2014;14(1):335.

21 Bauer TT, Welte T, Ernen C, Schlosser BM, Thate-Waschke I, de Zeeuw J, et al. Cost analyses of community-acquired pneumonia from the hospital perspective. Chest. 2005;128(4):2238-46.

22 Bartolome M, Almirall J, Morera J, Pera G, Ortun V, Bassa J, et al. A population-based study of the costs of care for community-acquired pneumonia. Eur Respir J. 2004;23(4):610-6.

23 Hak E, Grobbee DE, Sanders EA, Verheij TJ, Bolkenbaas M, Huijts SM, et al. Rationale and design of CAPITA: a RCT of 13-valent conjugated pneumococcal vaccine efficacy among older adults. Neth J Med. 2008;66(9):378-83.

24 Bonten MJ, Huijts SM, Bolkenbaas M, Webber C, Patterson S, Gault S, et al. Polysaccharide conjugate vaccine against pneumococcal pneumonia in adults. N Engl J Med. 2015;372(12):1114-25.

25 Fine MJ, Auble TE, Yealy DM, Hanusa BH, Weissfeld LA, Singer DE, et al. A prediction rule to identify low-risk patients with community-acquired pneumonia. N Engl J Med. 1997;336(4):243-50.

26 Lim WS, van der Eerden MM, Laing R, Boersma WG, Karalus N, Town Gl, et al. Defining community acquired pneumonia severity on presentation to hospital: an international derivation and validation study. Thorax. 2003;58(5):377-82.

27 Centraal Bureau voor de Statistiek. Kerncijfers postcodegebieden, 2008-2010. 2012. http://www.cbs.nl/nl-NL/menu/informatie/beleid/publicaties/ maatwerk/archief/2012/data-en-toelichting-postcodegebieden-2008-10.htm. Accessed 3 Sep 2015.

28 Tan SS, Bouwmans CA, Rutten FF, Hakkaart-van Roijen L. Update of the Dutch Manual for Costing in Economic Evaluations. Int J Technol Assess Health Care. 2012;28(2):152-8.

29 Mangen MJ, Rozenbaum MH, Huijts SM, van Werkhoven CH, Postma DF, Atwood $\mathrm{M}$, et al.. Cost-effectiveness of adult pneumococcal conjugate vaccination in the Netherlands. The European respiratory journal. 2015; ERJ00325-2015. doi: 10.1183/13993003.00325-2015.

30 Centraal Bureau voor de Statistiek. Statline. http://statline.cbs.nl/. Accessed 3 Sep 2015.

31 van de Garde EM, Oosterheert JJ, Bonten M, Kaplan RC, Leufkens HG. International classification of diseases codes showed modest sensitivity for detecting community-acquired pneumonia. J Clin Epidemiol. 2007;60(8):834-8.

32 Welte R, Feenstra T, Jager H, Leidl R. A decision chart for assessing and improving the transferability of economic evaluation results between countries. Pharmacoeconomics. 2004:22(13):857-76.

33 Marrie TJ, Lau CY, Wheeler SL, Wong CJ, Vandervoort MK, Feagan BG. A controlled trial of a critical pathway for treatment of community-acquired pneumonia. JAMA. 2000;283(6):749-55.

34 Whittle J, Lin CJ, Lave JR, Fine MJ, Delaney KM, Joyce DZ, et al. Relationship of Provider Characteristics to Outcomes, Process, and Costs of Care for Community-Acquired Pneumonia. Med Care. 1998;37(7):977-87.

35 Fine MJ, Pratt HM, Obrosky DS, Lave JR, Mclntosh L, Singer DE, et al. Relation between length of hospital stay and costs of care for patients with community-acquired pneumonia. Am J Med. 2000;109(5):378-85.

36 Cortoos PJ, Gilissen C, Laekeman G, Peetermans WE, Leenaers H, Vandorpe $L$, et al. Length of stay after reaching clinical stability drives hospitalcosts associated with adult community-acquired pneumonia. Scand I Infect Dis. 2013;45(3):219-26

37 Frei CR, Bell AM, Traugott KA, Jaso TC, Daniels KR, Mortensen EM, et al. A clinical pathway for community-acquiredpneumonia: an observational cohort study. BMC Infect Dis. 2011;11:188.

38 Hall MJ, DeFrances CJ, Williams SN, Golosinskiy A, Schwartzman A. National Hospital Discharge Survey: 2007 Summary. Natl Health Stat Rep. 2010:29:1-21

39 Kaplan V, Angus DC, Griffin MF, Clermont G, Scott Watson R, Linde-Zwirble WT. Hospitalized community-acquired pneumonia in the elderly: age- and sex-related patterns of care and outcome in the United States. Am J Respir Crit Care Med. 2002;165(6):766-72.

40 Cascini S, Agabiti N, Incalzi RA, Pinnarelli L, Mayer F, Arcà M, et al. Pneumonia burden in elderly patients: a classification algorithm using administrative data. BMC Infect Dis. 2013;13:559.

\section{Submit your next manuscript to BioMed Central and we will help you at every step:}

- We accept pre-submission inquiries

- Our selector tool helps you to find the most relevant journal

- We provide round the clock customer support

- Convenient online submission

- Thorough peer review

- Inclusion in PubMed and all major indexing services

- Maximum visibility for your research

Submit your manuscript at www.biomedcentral.com/submit
C Biomed Central 